\title{
Does Emotional Intelligence Get Affected from Some Biographical Factors- in Special Reference to Trainee Teachers?
}

\author{
Ravi Kant ${ }^{1, *}$, Samir Kumar Lenka ${ }^{2}$ \\ ${ }^{1}$ Maulana Azad National Urdu University, College of Teacher Education, Darbhanga, Bihar, INDIA \\ ${ }^{2}$ Nathulal Das B.Ed. College, Murshidabad, West Bengal \\ *Corresponding author: edu.ravikant@gmail.com
}

Received April 21, 2013; Revised May 25, 2013; Accepted July 16, 2013

\begin{abstract}
Emotions influence all aspects of human interaction. Emotional intelligence involves the ability to perceive accurately, the appraisal and expression of emotions, the ability to assess and / or generate feelings when they facilitate thought; the ability to understand emotions and emotional knowledge and the ability to regulate emotions to promote emotional and intellectual growth. A teacher in the classroom has to make adjustments in teaching strategies according to the nature and scope of curriculum and evaluate the success of teaching in terms of students' growth. Teaching is an emotional practice. Teachers' emotional commitments and connections to students energize and articulate everything that teachers do. In this investigation, with the help of Pearson's correlation quotient, an attempt has to find out the effect of biographical factors i.e. gender, SES, Type of institution on the emotional intelligence. This investigation revealed that gender does not play any role in development of emotional intelligence; also type of institution does not have any effect on emotional intelligence. But socio economic status shows a significant effect on emotional intelligence. With high socio economic status trainee teachers has high emotional intelligence; on other hand with low socio economic status some trainee teachers has low emotional intelligence.
\end{abstract}

Keywords: emotional intelligence, biographical factors, trainee teachers

Cite This Article: Kant, Ravi, and Samir Kumar Lenka, "Does Emotional Intelligence Get Affected From Some Biographical Factors- In Special Reference to Trainee Teachers?” American Journal of Educational Research 1, no. 6 (2013): 216-220. doi: 10.12691/education-1-6-8.

\section{Introduction}

It was earlier convention that only being intelligent is sufficient to live a healthy life and to get progress in life. Human is a rational animal so that there are many emotions in their life. These emotions control his activities and determine the path of success. Emotions are personal experiences that arise from complex interplay among physiological, cognitive and circumstantial variables. It is now well accepted that emotions are an essential tool for successful and fulfilling life. But if emotions are out of control, it can result in problems. In day-to-day life, they affect our relations with other people, our self-identity and our ability to complete a task. Emotional process is not an isolated phenomenon but component of general experience, constantly influencing and influenced by other processes going on at the same time. Emotions are personal experiences that arise from complex interplay among physiological, cognitive and situational variables. To be effective, the cognitive processes must be in control of the emotions, so that they work for rather than against. According to Mayer and Salovey [1], examining more complex manifestations of EI often requires understanding of individual's cultural framework. Also, all questions about emotions do not have the right answers. Salovey and Mayer [2] said that emotional intelligence involves the ability to perceive accurately, the appraisal and expression of emotions, the ability to assess and / or generate feelings when they facilitate thought; the ability to understand emotions and emotional knowledge and the ability to regulate emotions to promote emotional and intellectual growth. Goleman [3] viewed emotional intelligence as the ability to know and manage one's own emotions, recognize them in others and to handle relationships. It includes abilities such as being able to motivate one self and persist in the face of frustrations, to control impulses and delay gratifications, to regulate one's mood and keep distress from swamping the ability to think, to empathize and to hope. This definition of emotional intelligence includes self-control, zeal and persistence, and the ability to motivate oneself. Goleman [3] calls emotional intelligence "a master aptitude, a capacity that profoundly affects all other abilities, either facilitating or interfering with them". Goleman further asserts that "There is intelligence in the emotions and the senses in which intelligence can be brought to emotions............. Emotional intelligence is a master aptitude, a capacity that profoundly affects all other abilities, either facilitating or 
interfering with them. From a long time it is considered that teaching is a job of high repute and responsibility. Development of nation depends on its devoted citizens and these citizens are shaping in classroom so it is very clear that we need very devoted and sincere teachers to teach them. It is very important that only high emotionally intelligent peoples should come in this teaching profession. Being emotional intelligent for a teacher is very important because students always follow their teachers. Emotionally intelligent teacher can handle the emotion of teenagers effectively. Our classroom settings demand that student-teachers must learn how to appreciate and accept differences in emotional expressions and management among students. Emotions are an important part of one's personality. They determine the nature and effectiveness of the pattern of social interaction and also contribute to the psychological well-being of an individual. If our prospective teachers are emotionally intelligent, they will be able to express their emotions positively without threatening students or other persons. An attempt has been made in this study to find out that does emotional intelligence is related to some biographical factors?

\section{Literature Reviewed}

McDowell and Bell [4] found that lack of emotional intelligence skills lowered team effectiveness and created dysfunctional team interactions and most effective performers lost the best networking skills. Tapia and Marsh [5] found an overall significant main effect of gender and two-way interaction of gender - GPA on emotional intelligence. Annaraja and Jose [6] found that rural and urban B.Ed., trainees did not differ in their selfawareness, self-control, social skills and emotional intelligence. Devi and Uma [7] found that the parental education, occupation had significant and positive relationship with dimensions of emotional intelligence like social regard, social responsibility, impulse control and optimism. Harrod and Scheer [8] found that emotional intelligence levels were positively related to females, parents' education and household income. Amirtha and Kadhiravan [9] found that gender, age and qualification influenced the emotional intelligence of school teachers. Mishra [10] has studied the teaching work motivation among emotionally intelligent student-teachers. He found that as compared to high emotionally intelligent studentteachers; less emotionally intelligent student-teachers have less teaching work motivation. For highly emotionally intelligent student-teachers emotional intelligence was found to be positively related to teaching work motivation. But for less emotionally intelligent student-teachers the relationship was not significant. Updhyaya [11] has studied the personality of emotionally intelligent studentteachers on a sample of 78 student-teachers. It was found that as compared to low emotionally intelligent studentteachers, high emotionally intelligent student-teachers are more confident, persistent, supportive, enthusiastic and divergent. Parker et al [12] had studied the emotional intelligence of 464 Principals or Vice Principals from the elementary and secondary schools and found that women scored higher than men on the interpersonal dimension of emotional intelligence. Also task-oriented Principals are found to have impulse control, self awareness, assertiveness, self actualization, empathy, social responsibility, interpersonal relations, adaptability, problem solving, independence, stress tolerance, optimism and happiness, Gender, interpersonal, intrapersonal relations and adaptability were found to be the predicator of task oriented Principals and Vice Principals. Michael [13] has studied the emotional intelligence and faculty qualities necessary for success in a non-traditional classroom setting. Results revealed that there is no significant relationship between scores of emotional intelligence and scores on the student end-of-course evaluations. Also both faculty who scored high and low in assessment of emotional intelligence stressed flexibility and strong interpersonal relationship skills in the classroom. Faculty members who scored high on emotional intelligence assessment demonstrated more optimism than those who scored low on the assessment of emotional intelligence. Priyadarshini [14] found that there is a significant difference in the perception of male and female staff members with respect to their perception towards the components of emotional intelligence such as emotional sensitivity, emotional maturity and emotional competence. Majority of the staff members have got moderate emotional intelligence. Males and females are having moderate EQ though females were higher on emotional intelligence than men. It has been also found that there is significant difference between emotional intelligence with respect to educational level and emotional intelligence increases with increase in the span of experience and experience is found to be the most important factor of emotional intelligence. Analysis of teachers qualities by Sibia, Mishra \& Srivastava [15] shows that teachers who are affectionate and cooperative, have control over negative emotions and are friendly, were found to be emotionally successful. Children also admire teachers who are dedicated and show empathy and concern, are responsible and have a happy disposition. Creative, unbiased, confident, helpful, and optimistic and fearlessness were some other characteristics mentioned by the children while stating the favorite qualities of their favorite teacher. Children's responses indicate that they like teachers who are disciplined, regular, punctual, wellbehaved, available for students, serious about the studies, and make extra effort to reach out to each and every student. Okech [16] has examined the relationships among emotional intelligence, teacher's self-efficacy, length of teaching experience and age in a sample of South Texas Public School teachers. A significant positive relationship was found between emotional intelligence and teacher's self- efficacy. But there was no significant relationship between "emotional intelligence" and "length of teaching experience" and between "emotional intelligence" and "age". Male and female teachers are found to be different on "emotional intelligence". Perry, Ball and Stacey [17] have studied about a measure of emotional intelligence that relates directly to the work of teachers in schools and the levels of emotional intelligence held by teachers at the beginning of their career. Categorical finding based on gender, faculty, age-group and teaching focus shows that (i) a strong and significant gender difference exists on emotional intelligence reactions (ii) Emotional intelligence is directly related to the understanding of teaching motivation and self directed learning of studentteachers. Singh [18] has studied the emotional intelligence 
and adjustment of teachers working in different levels of education. He found that there is a significant positive relationship between emotional intelligence and adjustment. Teacher working in higher educational institution have better emotional intelligence and adjustment in comparison to the teachers in secondary and primary schools. Tucker, Sojka, Barone and McCarthy [19] found that EQ training program with the help of an instructor is essential for improvement as well as for assuring the success of any teaching and learning activity. Above studies found relationship between emotional intelligence and some other factors. In some cases if found significantly related and in some cases don't.

\section{Statement of the Problem}

Does emotional intelligence get affected from some biographical factors- In special reference to trainee teachers?

\section{Operational Definitions}

\subsection{Emotional Intelligence}

Emotional intelligence refers to emotional reasoning. It points to the ability to express one's emotions, understand one's own and others emotions, regulate one's own emotions and manage emotions of others.

\subsection{Biographical Factors}

The term biographical factors is denoting to all the biographical qualities of the particular population such as population, income, caste, gender, socio economic status, education etc.

\subsection{Trainee Teacher}

Here trainee teacher means who is under training of teaching profession.

\subsection{Govt. /Aided Clleges}

Govt. /Aided colleges are those colleges who receive financial support form provincial government.

\subsection{Self Fnance Clleges}

Self finance colleges are those colleges who did not receive any financial support from government. They have autonomy to produce finance at their own.

\section{Objectives of the Study}

Objectives of present investigation were as follow

1. To study the emotional intelligence of trainee teachers on the basis of gender.

2. To study the emotional intelligence of trainee teachers of govt. / aided colleges on the basis of SES.

3. To study the emotional intelligence of trainee teachers of govt. / aided colleges on the basis of gender.
4. To study the emotional intelligence of trainee teachers of self finance colleges on the basis of SES.

5. To study the emotional intelligence of trainee teachers of self finance colleges on the basis of gender.

\section{Hypotheses of the Study}

Following hypotheses were formulated to achieve the objectives

1. There will be no significant difference between emotional intelligence of male and female trainee teachers.

2. There will be significant positive correlation between emotional intelligence and SES of govt. /aided college's trainee teachers.

3. There will be no significant difference between emotional intelligence of govt. /aided college's trainee teacher on the basis of Low and High SES.

4. There will be no significant difference between emotional intelligence of govt. /aided college's trainee teacher on the basis of gender.

5. There will be significant positive correlation between emotional intelligence and SES of self finance college's trainee teachers.

6. There will be no significant difference between emotional intelligence of self finance college's trainee teacher on the basis of Low and High SES.

7. There will be no significant difference between emotional intelligence of self finance college's trainee teacher on the basis of gender.

\section{Delimitation of the Study}

1. The sample of this investigation constitutes of 200 trainee teachers.

2. This investigation was delimited to three districts i.e. Rampur, Moradabad, Jyotiba Phule Nagar of UP province of India.

3. This investigation was restricted to only two variable i.e. emotional intelligence and biographical factors.

\section{Research Method}

In this investigation Normative Survey method was used. For statistical treatment mean, standard deviation calculated and for finding significant relationship Pearson's correlation technique was used.

\section{Population and Sample}

In this investigation all trainee teachers of govt. /aided and self finance colleges running in three districts i.e. Rampur, Moradabad, Jyotiba Phule Nagar were considered as the population. After that 100 trainee teachers selected from govt. /aided colleges randomly. In the same manner 100 trainee teachers selected from self finance colleges. In both 100-100 group there were 50 male and 50 female trainee teachers. 


\section{Instruments Used}

Following instruments were used to achieving the objectives

1. Emotional Intelligence Scale by Akukool Hyde \& Upendra Dhar. This tool contains 34 items and language of this tool was both Hindi and English. Each item scored 5 for strongly agree, 4 for agree, 3 for neutral, 2 for disagree and 1 for strongly disagree.

2. Socio Economic Status Scale.

\section{Data Analysis and Findings}

Table 1 show that the mean of emotional intelligence of male and female trainee teachers is 137.15 and 136.90 respectively. T-value for both groups is 0.074 which is not significant at 0.05 level of significance. Hence it can be inferred that there is no significance difference between the emotional intelligence of male and female trainee teachers so hypothesis 1 stands accepted.

The statistical data mentioned in Table 2 show that emotional intelligence of govt. /aided college's trainee teacher is significantly positively correlated with socio economics status. So hypothesis 2 there will be significant positive correlation between emotional intelligence and SES of govt. /aided college's trainee teachers stand accepted.

Table 3 shows the means govt. /aided college's trainee teachers belong to High SES and Low SES are 26.45 and 23.65 respectively. t-value for both group is 2.24 which is significant at 0.05 level. So it can be said that SES play a vital role in developing emotional intelligence. So hypothesis 3, there will be no significant difference between emotional intelligence of govt. /aided college's trainee teacher on the basis of Low and High SES stands rejected.

Table 4 show that the mean of emotional intelligence of male and female trainee teachers is 137.20 and 136.90 respectively. $\mathrm{t}$-value for both group is 0.047 which is not significant at 0.05 level of significance. Hence it can be inferred that there is no significance difference between the emotional intelligence between male and female trainee teachers belongs to govt. /aided colleges, so hypothesis 4 stands accepted.

The statistical data mentioned in Table 5 show that emotional intelligence of self finance college's trainee teacher is significantly positively correlated with socio economics status. So hypothesis 5 there will be significant positive correlation between emotional intelligence and SES of self finance college's trainee teachers stands accepted.

Table 6 shows the means self finance college's trainee teachers belong to High SES and Low SES are 24.95 and 20.65 respectively. $t$-value for both group is 2.20 which is significant at 0.05 level. So it can be said that SES play a vital role in developing emotional intelligence also in case of self finance college's trainee teachers. So hypothesis 6 there will be no significant difference between emotional intelligence of self finance college's trainee teacher on the basis of Low and High SES stands rejected.

Table 7 show that the mean of emotional intelligence of male and female trainee teachers belongs to self finance college are 137.10 and 136.30 respectively. t-value for both group is 0.061 which is not significant at 0.05 level of significance. Hence it can be inferred that there is no significance difference between the emotional intelligence between male and female trainee teachers belongs to self finance colleges, so hypothesis 7 stands accepted.

Table 1. Mean, SD and t-value of Emotional Intelligence of Male and Female trainee teachers

\begin{tabular}{|cccccccc}
\hline VARIABLE & GROUP & $\mathrm{N}$ & MEAN & S.D. & 't' & LEVEL OF SIGNIFICANCE \\
EMOTIONAL INTELLIGENCE & MALE & 100 & 137.15 & 14.55 & 0.074 & $0.05 *$ \\
& FEMALE & 100 & 136.90 & 9.65 & - & \\
& & \\
\end{tabular}

*not significant

Table 2. Coefficient of correlation between emotional intelligence and socio economic status of govt. /aided college's trainee teachers

\begin{tabular}{|lcc|}
\hline DIMENSIONS & CO-EFFICIENT OF CORRELATION & LEVEL OF SIGNIFICANCE \\
SOCIO ECONOMIC STATUS & 0.305 & $0.05^{*}$ \\
*significant &
\end{tabular}

Table 3. Mean, SD and t-value of Emotional Intelligence of High and Low SES Govt. /Aided college's trainee teachers

\begin{tabular}{|cccccccc}
\multicolumn{2}{c}{ Table 3. Mean, SD and t-value of Emotional Intelligence of High and Low SES Govt. /Aided college's trainee teachers } \\
\hline VARIABLE & GROUP & N & MEAN & S.D. & 't' & LEVEL OF SIGNIFICANCE \\
EMOTIONAL INTELLIGENCE & HIGH SES & 29 & 26.45 & 7.21 & 2.24 & \\
& LOW SES & 29 & 23.65 & 5.75 & - & $0.05^{*}$ \\
\hline
\end{tabular}

Table 4. Mean, SD and t-value of Emotional Intelligence of Male and Female Govt. /Aided trainee teachers

\begin{tabular}{|ccccccc|}
\hline \multicolumn{1}{c}{ Table 4. Mean, SD and t-value of Emotional Intelligence of Male and Female Govt. /Aided trainee teachers } \\
\hline VARIABLE & GROUP & N & MEAN & S.D. & 't' & LEVEL OF SIGNIFICANCE \\
EMOTIONAL INTELLIGENCE & MALE & 50 & 137.20 & 15.50 & 0.047 & - \\
& FEMALE & 50 & 136.90 & 10.55 & - & $0.05^{*}$ \\
\hline
\end{tabular}

Table 5. Coefficient of correlation between emotional intelligence and socio economic status of self finance college's trainee teachers

\begin{tabular}{|c|c|c|}
\hline $\begin{array}{c}\text { DIMENSIONS } \\
\text { SOCIO ECONOMIC STATUS }\end{array}$ & $\begin{array}{c}\text { CO-EFFICIENT OF CORRELATION } \\
0.235\end{array}$ & $\begin{array}{c}\text { LEVEL OF SIGNIFICANCE } \\
0.05^{*}\end{array}$ \\
\hline
\end{tabular}

Table 6. Mean, SD and t-value of Emotional Intelligence of High and Low SES Self finance trainee teachers

\begin{tabular}{|ccccccc|}
\hline VARIABLE & GROUP & N & MEAN & S.D. & 't’ & LEVEL OF SIGNIFICANCE \\
EMOTIONAL INTELLIGENCE & HIGH SES & 29 & 24.95 & 8.91 & 2.20 & - \\
& LOW SES & 29 & 20.65 & 4.85 & - & $0.05^{*}$ \\
\hline *significant & & & & & & \\
\end{tabular}


Table 7. Mean, SD and t-value of Emotional Intelligence of Male and Female self finance trainee teachers

\begin{tabular}{|cccccccc}
\hline \multicolumn{4}{c}{ Table 7. Mean, SD and t-value of Emotional Intelligence of Male and Female self finance trainee teachers } \\
\hline VARIABLE & GROUP & $\mathrm{N}$ & MEAN & S.D. & 't' & LEVEL OF SIGNIFICANCE \\
EMOTIONAL INTELLIGENCE & MALE & 50 & 137.10 & 12.50 & 0.061 & - \\
& FEMALE & 50 & 136.30 & 9.55 & - & $0.05^{*}$ \\
\hline
\end{tabular}

\section{Findings' Interpretation}

1. There exists no significant difference between emotional intelligence of male and female trainee teachers.

2. There exists a significant positive correlation between emotional intelligence and SES of govt. /aided college's trainee teachers.

3. There exists a significant difference between emotional intelligence of govt. /aided college's trainee teacher on the basis of Low and High SES.

4. There exists no significant difference between emotional intelligence of govt. /aided college's trainee teacher on the basis of gender.

5. There exists a significant positive correlation between emotional intelligence and SES of self finance college's trainee teachers.

6. There exists a significant difference between emotional intelligence of self finance college's trainee teacher on the basis of Low and High SES.

7. There exists no significant difference between emotional intelligence of self finance college's trainee teacher on the basis of gender.

\section{Conclusion}

On the above findings it is clear that emotional intelligence play a very important role in the training period of trainee teachers. In this study it revealed that gender has nothing to play in case of emotional intelligence. But socio economic status plays a significant role in development of emotional intelligence. Who they are coming from high socio economic status are more emotionally intelligent this is because they have ample resources to use, while on other hand who were belong to low socio economic status show less emotional intelligence because they are facing the paucity of resources so they are always try to acquire basic need of daily life. Trainees in self finance colleges shows less positive relationship with emotional intelligence because it is general that in these self finance colleges fees are very high so only those candidate takes admission directly in these college without any examination while on government and aided college's case candidate belong to middle class or low socio economic status so they perform more on the emotional intelligence because they have to face competition in government and aided colleges.

\section{References}

[1] Mayer, J.D. \& Salovey, P. (1997). What is emotional intelligence? Cited in P. Salovey \& D. Sluyter (Eds), Emotional Development and Emotional Intelligence: Implications for Educators. New York:Basic Books.

[2] Salovey, P. \& Mayer. J.D. (1990). Emotional intelligence. Imagination, Cognition and Personality, 9, 185-211.

[3] Goleman, D. (1995). Emotional Intelligence: Why it can matter more than IQ. New York: Bantam Books.

[4] McDowell, J. O. \& Bell, E. D. (1997). Emotional Intelligence and Educational Leadership atEast Carolina University. Paper presented to the Annual Meeting of the National Council for Professors of Educational Administration, East Carolina University, August,1997.

[5] Tapia, M. and Marsh, G. (2001) Emotional Intelligence: The Effect of Gender, GPA and Ethnicity. Paper Presented at the Annual Meeting of the Mid-South Educational Research Association,Mexico. ( ED464086).

[6] Annaraja, P. and Jose, S. (2005) Emotional intelligence of B. Ed. trainees. Research and Reflections in Education 2, 8-16.

[7] Devi, U.L. and Uma, M. (2005) Relationship between the dimensions of emotional intelligence of adolescents and certain personal social variables. Indian Psychological Review 64, 01, 1120.

[8] Harrod N S \& Scheer S D (2005) An exploration of adolescent emotional intelligence in relation to demographic characteristics. From

http://www.findarticles.com/p/articles/mi-

m2248/is_159_40/ai_15950403/pg_9.

[9] Amirtha, M. and Kadheravan, S. (2006) Influence of personality on the emotional intelligence of teachers. Edu Tracks 5, 12, 25-29.

[10] Mishra, M. (2006). Teaching work motivation among emotionally intelligent student-teachers. Journal of Educational Studies, 4 (1 \& 2), 40-41.

[11] Upadhyaya, P. (2006). Personality of emotionally intelligent student-teachers. Journal of Educational Studies, 4 (1 \& 2), 37-39.

[12] Parker, J.D.A., Stone, H., Wood, L.M. (2006). Report on the Ontario Principal's Council Leadership Study. Ministry of Education and Training, Ontario, Canada.

[13] Michael, P. (2005). An analysis of emotional intelligence and faculty qualities necessary for success in non-traditional classroom setting. Ph.D. Walden University. Dissertation Abstract International, 2005, 66(7), 2465-A.

[14] Priyadarshini, R.R.G. (2005). A study of emotional intelligence among academic professionals. Journal of Management and Research, April 2005.

[15] Sibia, A., Srivastava, A.K. \& Mishra, G. (2004). Towards understanding emotional intelligence in the Indian context. Psychological Studies, 49, (2-3), 68-77.

[16] Okech, Allan P. (2004). An exploratory examination of the relationships among emotional intelligence, elementary school science teachers, self-efficacy, length of teaching, experience, race/ ethnicity, gender and age. Ed.D., Texas A \& M University, Kingsville. Dissertation Abstract International, 2005, 65(8), 2902A.

[17] Perry, Ball \& Stacey (2004). Cited in Chriss Perry and Ian Ball (2005). Emotional Intelligence and teaching: Further validation evidence. Issues in educational Research, 15.

[18] Singh R. (2003). Study of Emotional Intelligence and adjustment of teachers in different levels of education. M.Ed. Dissertation, D.E.I. Agra.

[19] Tucker, M.L., Sojka, J.Z., Barone, F.J. \& McCarthy, A.M. (2000). Training tomorrow's leaders: Enhancing the emotional intelligence of business graduates. Journal of Education for Business, 75(6), 331-338. 